\title{
A leitura do hipertexto sob a perspectiva da Teoria da Enunciação
}

\author{
The reading of the hypertext in the perspective of the Theory of Enunciation
}

Jornalista. Doutoranda em Letras (Associação Ampla UCS e UniRitter). Professora na Faculdade Murialdo.
E-mail: julirossa@hotmail.com
RESUMO: Este artigo tem como objetivo realizar o cruzamento interdisciplinar das teorias da enunciação e do hipertexto. 0 estudo, de natureza teórica, caracteriza-se por ser uma análise que interliga as contribuições da teoria da enunciação de Émile Benveniste com teorias sobre hipertexto, pela ótica de autores como Lúcia Santaella, Pierre Lévy, Alex Primo e George Landow. Observamos que as categorias de pessoa, tempo e espaço as quais Benveniste debita a subjetividade da linguagem - potencializam-se no hipertexto. Essa potencialização, que é uma das características do ciberespaço pela infinidade de elos multiconectados, induz a uma forma especial de leitura desses hipertextos. Dessa forma, propomos o termo hipersubjetividade da linguagem para tratar do discurso no ambiente virtual, o qual possui um leitor diferenciado e imersivo no complexo cenário do ambiente virtual.

PaLAVRAS-CHAVE: Enunciação; Subjetividade da linguagem; Leitura; Benveniste; Hipertexto.

ABSTRACT: This article aims to conduct the interdisciplinary crossing of the theories of enunciation and the hypertext. The study, of a theoretical nature, is characterized by being an analysis which links the contributions of Émile Benveniste's theory of enunciation with theories about hypertext, from the perspective of authors such as Lúcia Santaella, Pierre Lévy, Alex Primo and George Landow. We observed that the categories of person, time and space - which Benveniste debits the subjectivity in language - are enhanced in the hypertext. This enhancement, which is one of the characteristics of cyberspace by the countless multiconected links, leads to a particular way of reading these hypertexts. Thus, we propose the term hypersubjectivity in language to treat speech in the virtual environment, which has a distinctive and immersive reader in the complex scenario of the virtual environment.

KEYworDS: Enunciation; Subjectivity in language; Reading; Benveniste; Hypertext. 


\section{Introdução}

$\mathrm{M}$

uitas foram as contribuições da teoria da enunciação para os estudos linguísticos, principalmente com a publicação das obras de Émile Benveniste. As ideias do linguista francês já foram bastante exploradas, mas, no que se refere a sua aplicação especificamente à leitura, ainda há muito que construir.

Neste artigo, lanço conjecturas para discussão, desenvolvendo o cruzamento da teoria da enunciação de Benveniste - com percepções sobre o entendimento da leitura dentro da sua teoria - e as teorias sobre hipertexto. $\mathrm{Na}$ primeira parte, abordo aspectos gerais da teoria da enunciação, com enfoque aos textos de Benveniste "A natureza dos pronomes" e "Da subjetividade na linguagem", da obra Problemas de linguística geral I (1988); e "O aparelho formal da enunciação", da obra Problemas de linguística geral II (1989). Em seguida, exponho diferentes aspectos das teorias envolvendo o hipertexto, com destaque às características da leitura no ambiente virtual. $\mathrm{A}$ terceira seção é dedicada ao ponto principal deste estudo, que é a leitura do hipertexto sob a perspectiva de Benveniste. Nesse tópico, a leitura é analisada principalmente mediante o potencial de intensificação da subjetividade da linguagem que julgo haver o hipertexto.

\section{Alguns aspectos da teoria da enunciação de Benveniste}

Émile Benveniste é reconhecido por ter apresentado avanços às teorias de Saussure, dando relevância ao sujeito nos processos linguísticos. O que Beveniste propõe é uma ideia de linguagem que dê ao indivíduo o status de sujeito: "é um homem falando que encontramos no mundo, um homem falando com outro homem, e a linguagem ensina a própria definição do homem" (BENVENISTE, 1988, p. 285). Ou seja, o homem é um ser de linguagem. Mas não o é sozinho, precisa do outro. E é a linguagem que viabiliza a existência de $e u$-tu, como sujeitos, mediante a condição de interação. "É na linguagem e pela linguagem que o homem se constitui como sujeito; porque só a linguagem fundamenta na realidade, na sua realidade que é a do ser, o conceito de 'ego'"' (BENVENISTE, 1988, p. 286).

Por isso Benveniste atribui a característica da singularidade aos estudos da linguagem. Sendo individual, o locutor elege mecanismos próprios, em uma ação que é sempre inédita e que nunca se repete. Nesse contexto, o autor discute sobre a subjetividade da linguagem, como "[...] a capacidade do locutor para se propor como sujeito." (BENVENISTE, 1988, p. 286).

Para a compreensão desses aspectos, em especial, me detenho em três dos textos de Benveniste: "A natureza dos pronomes" e "Da subjetividade na linguagem”, da obra Problemas de linguística geral I (1988); e "O aparelho formal da enunciação”, da obra Problemas de linguística geral II (1989).

\subsection{Sobre a natureza dos pronomes}

Sendo a linguagem um ato individual, quem a executa é o sujeito, que se representa na linguagem pelas marcas de pessoa do discurso, como as associadas aos pronomes. Em sua teoria, Benveniste (1988) destaca a ideia ingênua da universalidade dos pronomes:

A universalidade dessas formas e dessas noções faz pensar que o problema dos pronomes é ao mesmo tempo um problema de linguagem e um problema de línguas por ser, em primeiro lugar, um problema de linguagem. É como fato de linguagem que o apresentaremos aqui, para mostrar que os pronomes não constituem uma classe unitária, mas espécies diferentes segundo o modo de linguagem do qual são os signos. Uns pertencem à sintaxe da língua, outros são característicos daquilo a que chamaremos as "instâncias do discurso", isto é, os atos discretos e cada vez únicos pelos quais a língua é atualizada em palavra por um locutor. (p. 277). 
Segundo o autor, a pessoalidade somente tem validade para $e u$ e $t u$, e não para ele, pertencentes às instâncias do discurso. Essa diferença sobressai sempre da noção de $e u$. "As instâncias de emprego de $e u$ não constituem uma classe de referência [...]. Cada eu tem a sua referência própria e corresponde cada vez a um ser único, proposto como tal" (BENVENISTE, 1988, p. 278).

Benveniste (1988, p. 278) questiona: “Qual é, portanto, a 'realidade' à qual se refere eu e tu?" O autor é taxativo na resposta: "Unicamente uma 'realidade de discurso', que é coisa muito singular. Eu só pode definir-se em termos de 'locução', não em termos de objetos, como um signo nominal" (p. 278). Nessa perspectiva, o eu só pode ser identificado na prática do discurso que o contém, pois não tem valor a não ser na instância de discurso na qual é produzido, definindo-se pela simetria com o $t u$. Existe, nesse processo, uma dupla instância: a do eu como referente e a do eu referido na instância do discurso. Dessa forma, eu e tu são uma categoria de linguagem que se relacionam com a sua posição na linguagem (BENVENISTE, 1988).

À instância de discurso que constitui o traço que une eu/tu, instauram-se outros indicadores, como pronomes, advérbios e locuções adverbiais, cujas relações são essenciais com a presente instância de discurso (BENVENISTE, 1988). Nesse sentido, é preciso que se considere o "sujeito que fala" no discurso:

É ao mesmo tempo original e fundamental o fato de que essas formas 'pronominais' não remetem à 'realidade' nem a posições 'objetivas' no espaço ou no tempo, mas à enunciação, cada vez única, que as contém, e reflitam assim seu próprio emprego. A importância da sua função se comparará a natureza do problema que servem para resolver, e que não é senão o da comunicação intersubjetiva. A linguagem resolveu esse problema criando um conjunto de signos 'vazios', não referenciais com relação à 'realidade', sempre disponíveis, e que se tornam 'plenos' assim que um locutor os assume em cada instância do seu discurso (BENVENISTE, 1988, p. 280).
Esses chamados signos vazios não afirmam nada sozinhos. Funcionam fornecendo, sobretudo, um instrumento de uma conversão da linguagem em discurso. $\mathrm{O} e u$, como pessoa única, possibilita que cada locutor se proponha como sujeito de seu discurso. "É identificando-se como pessoa única pronunciando eu que cada um dos locutores se propõe alternadamente como 'sujeito'” (BENVENISTE, 1988, p. 280-281). Dessa forma, o que vale é a situação do discurso, bem como a apropriação que faz o locutor.

Benveniste (1988) fala das instâncias pessoais do discurso: o eu como pessoa subjetiva, o tu como pessoa não-subjetiva e o ele como não-pessoa. Em relação ao papel da terceira pessoa, o autor a apresenta, pela sua função e natureza, como completamente diferentes de eu e $t u$. A terceira pessoa apresenta características distintivas, é uma "não-pessoa":

$1^{\circ}$. de se combinar com qualquer referência de objeto; $2^{\circ}$. de não ser jamais reflexiva da instância de discurso; $3^{\circ}$. de comportar um número às vezes bastante grande de variantes pronominais ou demonstrativas; $4 \stackrel{\text { a }}{\text {. de não ser }}$ compatível com o paradigma dos termos referenciais como aqui, agora, etc (BENVENISTE, 1988, p. 283).

Ainda em relação à não-pessoa, é preciso situar também o processo que ocorre em nós e vós. Para Benveniste, o nós não corresponde ao plural de eu, nem o vós corresponde ao plural de tu. Ocorre, nesses casos, a união de um eu com um não-eu:

Tanto o uso de nós se amplifica em uma pessoa mais solene, com maior autoridade no nós majestático, quanto se amplifica em uma pessoa mais difusa com contornos indefinidos no nós de orador ou de autor. A mesma análise é feita para vós, tanto no uso coletivo quanto no uso de polidez a passagem do tu ao vós exprime pessoa generalizada (FLORES et al., 2008, p. 79, grifo do autor).

No entanto, a gramática tradicional insiste em qualificar os pronomes pessoais da mesma forma. Porém, a noção de pessoa não está presente em 
todos. Na enunciação, torna-se fundamental um olhar pormenorizado diante das características de cada pessoa: o $e u$, como um ser subjetivo, que instaura um tu não-subjetivo; ambos em oposição a ele, que não corresponde à marca de pessoa. (FLORES et al., 2008, p. 79). Nessa concepção, é possível, segundo Benveniste (1988, p. 283), realizar a seguinte diferenciação: a língua como repertório de signos e sistema, de um lado, e a língua como atividade manifestada nas instâncias de discurso por índices próprios.

\subsection{Sobre a subjetividade da linguagem}

Se pensarmos na língua como atividade manifestada nas instâncias de discurso, levando-se em conta pessoa, tempo e espaço, não podemos fugir das discussões acerca da subjetividade da linguagem. Para Benveniste, a subjetividade se determina pelo status linguístico da "pessoa".

A linguagem só é possível porque cada locutor se apresenta como sujeito, remetendo a ele mesmo como eu no seu discurso. Por isso, eu propõe outra pessoa, aquela que, sendo embora exterior a "mim", torna-se o meu eco - ao qual digo tu e que me diz tu. A polaridade das pessoas é na linguagem a condição fundamental, cujo processo de comunicação, de que partimos, é apenas uma consequência totalmente pragmática (BENVENISTE, 1988, p. 286).

Assim, de acordo com o autor, os pronomes pessoais são marcas de subjetividade na linguagem, já que se distinguem de todas as designações que a língua articula, não remetendo nem a um conceito nem a um indivíduo. Segundo a teoria enunciativa do autor, o eu não denomina nenhuma entidade lexical; ele se refere ao ato de discurso individual no qual é pronunciado e designa o locutor. É um termo que não pode ser identificado fora da instância de discurso; tem referência da realidade do discurso. (BENVENISTE, 1988).

Além dos pronomes pessoais, outras classes de pronomes também evidenciam a subjetividade da linguagem. É o caso dos "[...] indicadores da deíxis, demonstrativos, [...] que organizam as relações espaciais e temporais em torno do "sujeito" tomado como ponto de referência: 'isto, aqui, agora' [...], etc." (BENVENISTE, 1988, p. 288).

A expressão da temporalidade contribui para a subjetividade da linguagem, já que a língua se distingue sempre em "tempos". Para Benveniste (1998), a noção de tempo é fundamental em todas as línguas, como é notório em relação aos advérbios e às complexas flexões verbais. Sob esse ponto de vista, por exemplo, o presente tem como referência temporal um dado linguístico, existindo a coincidência do acontecimento descrito com a instância de discurso que o descreve, situação que ocorre somente no interior do discurso.

\subsection{0 aparelho formal da enunciação}

O emprego das formas tem lugar consagrado nas nossas descrições linguísticas, aponta Benveniste (1989). O autor diz que o aparelho formal da enunciação utiliza condições de emprego das formas que não são idênticas ao emprego da língua. Por meio do emprego da língua, o sujeito a coloca em funcionamento, produzindo a enunciação por um ato individual de utilização.

Para Benveniste (1989), esse processo pode ser estudando sob diferentes aspectos, sendo os três seguintes os principais:

a) o ato da enunciação em si: "é a realização vocal da língua" (p. 82), como ato individual;

b) visão do sentido que se transforma em palavra, ou seja, as situações em que o ato se realiza;

c) os instrumentos de sua realização individual, como um processo de apropriação. "O locutor se apropria do aparelho formal da língua e enuncia sua posição de locutor por meio de índices específicos, de um lado, e por meio de procedimentos acessórios, de outro" (Ibidem, p. 84). 
O locutor implanta o outro diante de si, criando a necessidade de referir pelo discurso. É constitutivo da enunciação que cada instância do discurso inaugure um centro de referência interno, como os índices de pessoa eu, tu e $e l e^{1}$. Dessa maneira, fica evidente que sem referência não existe enunciação.

\section{Hipertexto enquanto discurso no ciberespaço ${ }^{2}$}

É importante se destacar que discurso é discurso em qualquer instância, em qualquer plataforma, seja ela presencial ou virtual. Não podemos pensar a enunciação na atualidade sem que a relacionemos aos processos linguísticos dos ambientes virtuais instaurados no contexto do ciberespaço. Atendendo aos propósitos deste estudo, nesta seção, primeiramente apresento algumas considerações sobre o texto no ambiente virtual, chamado hipertexto. Após, falo sobre características da leitura no contexto do hipertexto, já que um dos objetivos deste artigo é trabalhar com essa questão também sob a luz das teorias da enunciação de Benveniste.

\subsection{Características do hipertexto}

Uma das faces fundamentais da cibercultura, segundo Lúcia Santaella (2004, p. 44), é a face da linguagem, que é a linguagem da hipermídia, caracterizada pela mescla de textos, imagens, vídeos, sons em um todo complexo. Seguindo os passos de Lévy (1993), utilizaremos o termo hipertexto também como significado de hipermídia.

Devemos falar de multimídia interativa? De hipermídia? De hipertexto? Escolhemos aqui o termo hipertexto deixando claro que ele não exclui de forma alguma a dimensão audiovisual. Ao entrar em um espaço interativo e reticular de manipulação, de associação e leitura, a imagem e o som adquirem um estatuto de quase-textos (p. 33).

\footnotetext{
Conforme mencionado anteriormente no item 2.1

2 Parte do conteúdo aqui presente sobre hipertexto foi retirado da minha dissertação de mestrado (ROSSA, 2010).
}

A internet nasceu e cresceu baseada no modelo hipertextual de registro, armazenamento e divulgação de dados. Marianne Cavalcante (2004) diz que, com a tecnologia evoluída a partir da década de 1980, surgiu uma nova geração de sistemas, com características de hipermídia. Nessa fase, que se estende até hoje, "a preocupação centra-se na adequação das interfaces com os usuários e os sistemas" (CAVALCANTE, 2004, p. 164). Essa evolução permitiu o desenvolvimento de ferramentas baseadas na cooperação ${ }^{3}$.

Nessa fase, a web ganhou a denominação de web 2.0, a segunda geração de serviços online. Segundo Alex Primo (2007, online), a web 2.0 caracterizase por “(...) potencializar as formas de publicação, compartilhamento e organização de informações, além de ampliar os espaços para a interação entre os participantes do processo". Para Aquino (2009), esses recursos possibilitam o background de atuação dos usuários que, via hipertexto, vêm gerenciando a informação na web.

O hipertexto, ao contrário do que se possa imaginar, sempre fez parte dos processos de fala e escrita. A vida cotidiana é plena de situações hipertextuais. Numa conversa entre amigos, por exemplo, um assunto pode incentivar outros, podem ocorrer interrupções, esquecimentos, com retorno à conversa anterior. Segundo Lévy (1999a), uma enciclopédia pode ser considerada um hipertexto. Não existe uma ordem precisa de leitura. Um item pode levar a outro (sumário, tabelas, notas de rodapé, etc.). Nesse sentido, uma biblioteca também funciona como um hipertexto, já que fichários e catálogos constituem os instrumentos de navegação global.

No entanto, o suporte digital traz uma diferença considerável ao hipertexto: todas as operações ocorrem de modo muito rápido. Além disso,

${ }^{3}$ São exemplos de cooperação entre usuários na rede os blogs e as enciclopédias online escritas de forma conjunta pelos usú́cios, como a Wikipédia (wWwilipedicom), além de sites de publicação de

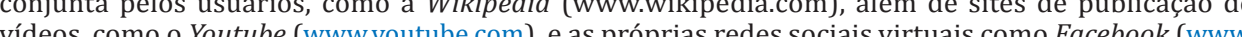
. facebook.com) e Twitter (www.twitter.com). 
por meio da digitalização, é possível associar diferentes tipos de mídia. Nesse sentido, o hipertexto digital, para Lévy (1999a, p. 56), "seria definido como informação multimodal disposta em uma rede de navegação rápida e 'intuitiva'."

Talvez por ser um texto que apresenta muitas facetas, sua definição implique tantos argumentos. De acordo com Pierre Lévy (1993):

Tecnicamente, um hipertexto é um conjunto de nós ligados por conexões. Os nós podem ser palavras, páginas, imagens, gráficos ou pares de gráficos, sequências sonoras, documentos complexos que podem eles mesmos ser hipertextos. Os itens de informação não são ligados linearmente, como uma corda com nós, mas cada um deles, ou a maioria, estende suas conexões em estrela, de modo reticular. Navegar em um hipertexto significa portanto desenhar um percurso em uma rede que pode ser tão complicada quanto possível. Porque cada nó pode, por sua vez, conter uma rede inteira (p. 33).

A definição de Levy nos faz pensar sobre a complexidade e extensão que o hipertexto pode atingir, devido a gama de possibilidades que nos fazem acreditar em algo revelador de infinitas interconexões. $\mathrm{O}$ autor, em outra publicação, acrescenta que:

O hipertexto é um texto em formato digital, reconfigurável e fluido, (...) composto por blocos elementares ligados por links que podem ser explorados em tempo real na tela. A noção de hiperdocumento generaliza, para todas as categorias de signos (imagens, animações, sons etc.) o princípio da mensagem em rede móvel que caracteriza o hipertexto. (LÉVY, 1999a, p. 27).

Os conceitos por si já falam muito das características do hipertexto. Porém, além da definição, é preciso que compreendamos outras peculiaridades, como os elementos estruturais, técnicos, mudanças nos papéis de autor e leitor, de escrita e leitura hipertextuais.

Do ponto de vista informático, o hipertexto exige recursos técnicos, dos quais resultam a sua hibridez. O hipertexto apoia-se no método de base de dados, de representação de conhecimentos e nos procedimentos de ligação intuitiva de interfaces. Essas características provocam a sua unidade operatória original. Laufer e Scavetta (19--) propõem um sistema hipertextual ideal, com os seguintes pontos:

- a base de dados é uma rede de nós textuais (e/ou gráfico) que pode ser pensado como um hiperdocumento ou um conjunto complexo de documentos;

- as ligações entre os nós são geradas pelo computador ${ }^{4}$ e vários nós podem ser ligados a um só. Estas ligações não se limitam a puras ligações hierárquicas:

- as janelas abertas no écran correspondem, de forma unívoca, aos nós no interior da base de dados e cada uma delas afixa o nome ou o título do elemento de informação que contém. Só um pequeno número de nós, no entanto, está simultaneamente "aberto" no écran, sob a forma de janelas;

- podem-se efectuar as operações estandardizadas de um sistema de gestão de janelas: podem-se reposicionar as janelas, modificar-lhes as dimensões, fechá-las e pô-las inactivas, sob a forma reduzida de pequenos ícones-janelas: - as janelas podem conter vários ícones de ligação que apontam para outros nós presentes na base de dados. 0 ícone de ligação contém, num campo, um texto curto, que sugere o conteúdo do nó para o qual o ícone de ligação provoca a procura e a visualização, numa nova janela, do nó que com ela se relaciona;

- o utilizador pode facilmente criar nós e novas ligações, seja para inserir novos nós (de anotação, de comentário, etc.), seja para associar nós já existentes. (p. 71-72).

Existe liberdade para o usuário transitar entre os documentos hipertextuais, percorrendo uma base, conforme Laufer e Scavetta (19--), de três maneiras: seguindo as ligações e abrindo as janelas, uma atrás das outras, para examinar o seu conteúdo; procurando na rede algumas cadeias, palavras-chave, ou valores de atributo; ou ainda, utilizando um navegador de

${ }^{4}$ Nos dias de hoje, não somente pelo computador conectado, mas por dispositivos móveis, como smartphones e tablets. 
internet que permite visualizar o hiperdocumento em forma de gráfico, em nível local ou global, mostrando, assim, o conteúdo dos nós e de seus elos.

Para demonstrar os múltiplos contextos em que o hipertexto está inserido, Landow (1993) realizou três diferentes relações, com: intertextualidade, polifonia e descentramento. Na relação com a intertextualidade, o autor diz que o hipertexto é fundamentalmente intertextual. A intertextualidade é uma característica hipertextual mesmo em ambientes não eletrônicos, como os livros, por exemplo. Já no ambiente virtual, essa característica se acentua pelas infinitas possibilidades de relações existentes entre os nós hipertextuais.

Em analogia com a polifonia, Landow (1993) diz que o hipertexto não tolera uma voz tirana, única. $\mathrm{O}$ autor se utiliza dos estudos de Bakhtin sobre o romance dialógico e polifônico, para explicar que o hipertexto não se constituiu como totalidade de uma só consciência, mas sim como a totalidade das interações de várias consciências, das quais nenhuma se faz inteiramente objeto de outra. A voz do hipertexto é sempre a que nasce no momento da leitura, daquilo que emerge desse processo.

Na relação com o descentramento, Landow (1993) afirma que uma das características fundamentais do hipertexto é a sua composição em forma de blocos de outros textos coligados entre si e que não são organizados em um eixo principal. Os leitores se movem através de uma rede de textos, cujo centro se desloca continuamente e, por consequência, também se desloca o princípio de organização. $\mathrm{O}$ hipertexto fornece um sistema multifocal, cujo ponto de focalização transitório depende do leitor, que se torna um leitor autenticamente ativo.

No sistema hipertextual, texto, autor e leitor possuem características especiais, pela disposição hipertextual em nós. Para Cavalcante (2004), o que torna um texto "hiper" são seus links. Eles têm papel relevante na construção de sentido dos hipertextos. Segundo a autora, são eles que garantem a arquitetura do texto no ambiente virtual, já que monitoram o leitor para um exterior discursivo. Os links (nós) promovem a ligação entre os fragmentos de informação. As ligações realizadas através dos links “...promovem a abertura para outros textos, mas nunca qualquer texto" (CAVALCANTE, 2004, p. 166). Ou seja, as conexões entre os textos seguem uma motivação.

\subsection{A leitura do hipertexto}

O hipertexto implanta uma nova forma de leitura e novas competências ao leitor. Se compararmos com as técnicas anteriores de leitura, a digitalização introduz uma pequena revolução:

Não é mais o navegador que segue os instrumentos de leitura e se desloca fisicamente no hipertexto, virando as páginas, deslocando os volumes pesados, percorrendo a biblioteca. Agora é um texto móvel, caleidoscópio, que apresenta suas facetas, gira, dobra-se e desdobra-se à vontade frente ao leitor. (LÉVY, 1999a, p. 56).

Laufer e Scavetta (19--, p. 5) dizem que o conteúdo do hipertexto pode ser lido de diferentes maneiras e que os nós e ou elementos de informação, "[...] em vez de estarem ligados uns aos outros como as carruagens de um comboio, estão marcados por elos semânticos que permitem passar um para o outro." Esses elos, como também mostrou Lévy (1999a), estão ancorados em zonas, como numa palavra, frase ou imagem.

Os elos, ou nós, segundo Sérgio Costa (2009), fazem com que o hipertexto seja uma "organização de unidades de informação por meio de associações interligadas", que possui ligações (links/hiperlinks) para diferentes partes do mesmo documento ou ainda para documentos diferentes e que podem ser lidos de diversas maneiras e por diversos caminhos.

Edson Bugay e Vânia Ulbricht (2000) definem o hipertexto pelo viés da leitura. Para os autores, o hipertexto é um tipo específico de hipermídia 
interativo, não-linear, que permite "ao usuário trabalhar em seu próprio ritmo, nível e estilo, adequado as suas características e interesses" (p. 41). Através da estrutura flexível do hipertexto, existe uma lógica diferente da leitura linear. $O$ usuário também pode reaproximar informações e comparálas, tendo a possibilidade de adquirir diferentes abordagens sobre um mesmo assunto.

Segundo Landow (1993, p. 7), uma leitura de um artigo na internet, com recursos hipertextuais, apresenta uma riqueza surpreendentemente maior do que a mesma leitura no papel, “[...] no qual a totalidade poderia ser mais importante do que o texto". O conteúdo da leitura estaria inserido em diferentes contextos, diferentemente de sua forma impressa.

Isso ocorre, segundo Cavalcante (2004), porque o leitor torna-se também autor:

A tessitura hipertextual funciona como uma representação das redes de sentido que estabelecemos na leitura de um texto qualquer. Os links seriam as representações dessas redes que o autor propositalmente apresenta ao leitor, como estratégia de marcar seu próprio percurso enquanto autor, seu estilo, sua história, seu lugar de autoria, e delineando que caminhos o leitor pode perseguir nesta(s) leitura(s) (p. 167).

Os textos interligados no ambiente virtual, mesmo que dotados de links especificamente planejados, não têm a capacidade de limitar uma segmentação de leitura. Para Landow (1993), o hipertexto muda os conceitos de início e fim de um texto. O leitor pode iniciar o percurso de vários pontos diferentes, escolhendo diferentes destinos, além da possibilidade de continuar realizando adições ao texto, expandi-lo, deixá-lo com algo a mais de quando iniciaram a lê-lo. Assim, o sentido de "fim" é o que sofre maior alteração.

De acordo com Lúcia Santaella (2004), a linearidade do texto é quebrada através da operação de associação entre nós e nexos. Os nós são unidades que, além do texto verbal, estão integrados em tecnologias que são capazes de produzir som, fala, ruído, gráficos, desenhos, fotos, vídeos etc. As conexões estabelecidas por esses nós podem ser de múltiplos tipos: entre nós, entre nó e texto, entre texto e nós etc. 0 trajeto a ser seguido é um percurso de descobertas. Cada link ultrapassado abre um caminho de possibilidades.

As conexões entre os nós nos sistemas hipertextuais geram uma espécie de "cadeia de montagem", de acordo com Landow (1993). "Depois de ser inserido em uma rede de coligamentos eletrônicos, um documento não existe mais como uma entidade autônoma" (p. 108)5. 0 relacionamento com outros textos é inevitável. Um documento em rede é um potencial colaborador para outros documentos do mesmo sistema. O hipertexto, dessa maneira, em relação ao texto impresso, coloca em questão a sequência pré-fixada, o início e o fim predefinidos, o "tamanho" do texto e a unidade do todo.

No hipertexto, autor e leitor realizam ações coletivas. Ambos os papéis sofrem importantes modificações, se comparados com o texto escrito no papel. São as novas configurações que o hipertexto traz para as duas partes. Segundo Pierre Lévy (1996), o navegador participa da redação ou pelo menos da edição do texto, como parte ativa na sua organização final.

Dessa forma, Levy (1999a, p. 61) diz que "com o hipertexto, toda leitura é uma escrita potencial." A leitura/escrita é organizada conforme os próprios interesses do leitor. O material de leitura, para Landow (1993, p. 15) tornase "um documento-índice que o leitor utiliza para orientar-se e para decidir para que lugar pretende ir". É um sistema descentralizado e ao mesmo tempo focalizado, já que o hipertexto transforma qualquer documento, com mais de uma conexão para outro, em um centro transitório.

Para transitar no território hipertextal, o leitor, segundo Lúcia Santaella (2004), torna-se um leitor imersivo. Para a autora:

${ }^{5}$ Minha tradução para: "Dopo essere stato inserito in uma rete di collegamenti elletronici, un documento non esiste più come entità autonoma." 
É uma atividade nômade de perambulação de um lado para o outro, juntando fragmentos que vão se unindo mediante uma lógica associativa e de mapas cognitivos personalizados e intransferíveis. É, pois, uma leitura topográfica que se torna literalmente escritura, pois, na hipermídia, a leitura é tudo e a mensagem só vai se escrevendo na medida em que os nexos são acionados pelo leitor-produtor"(p. 175).

Esse tipo de leitura, de acordo com a autora, faz emergir também transformações sensórias, perceptivas e cognitivas, que têm um ritmo marcado pela agilidade dos movimentos multidirecionais, "com que o olhar do infonauta varre ininterruptamente a tela, na movimentação multiativa do ponteiro do mouse e na velocidade com que a navegação é executada." (SANTAELLA, 2004, p. 181). Essas características substituem o automatismo cerebral pela mente distribuída, que realiza várias operações ao mesmo tempo, como ler, escutar e olhar.

\section{A leitura do hipertexto sob a perspectiva de Benveniste}

As características do hipertexto o tornam especial em relação às mudanças que ocorrem em relação à leitura dos discursos nele presentes, em comparação ao texto tradicional, que é linear. Se os discursos dos textos no formato linear são subjetivos, não haveria no ciberespaço - pelas especificidades apresentadas anteriormente -, uma intensificação dessa subjetividade? Acredito que as teorias enunciativas de Benveniste podem ajudar nessa reflexão.

\subsection{Reflexões sobre leitura em Benveniste}

Refletindo sobre o que diz Benveniste principalmente sobre a subjetividade na linguagem, é possível que entendamos o processo de leitura da palavra ou de qualquer outra imagem acústica (SAUSSURE, 1989) por meio da aceitação de que o ato da leitura é também um ato subjetivo individual, que vai depender dos diferentes fatores que envolvem a atualização do discurso; abrange a aceitação de situar-se no tempo do locutor (do eu que produz aquele discurso). Ao lermos, reconhecemos as formas e a relação dessas formas para a obtenção do sentido do discurso. Assim, pode-se entender o sentido do uso por quem usa o aparelho formal da enunciação.

Se a enunciação envolve uma ação inédita e irrepetível, cabe à leitura também ser sempre algo original em cada ocorrência, mesmo que essa leitura seja efetuada sobre um mesmo texto em momentos diferentes. $\mathrm{O}$ tempo já não é mais o mesmo, pois nós, leitores, vivemos modificações a todo o instante. Dessa forma, cada leitura inaugura um novo processo de significação do enunciado. Nesse sentido, não somente o locutor se propõe como sujeito, mas também o leitor.

\subsection{Proposta de análise e cruzamentos teóricos}

As teorias enunciativas de Benveniste são de grande relevância para a área da linguística. No entanto, também podem auxiliar em análises de outras áreas, como é o caso da comunicação. Destaco que o que apresento aqui é uma proposta inicial que necessita ainda de amadurecimento para maior validação.

Neste artigo, que se propõe a apontar aspectos da teoria de Benveniste - em especial sobre a leitura - e, ainda, sobre as teorias que envolvem o hipertexto - em especial a leitura do hipertexto -, procuro fazer alguns cruzamentos sobre essas realidades.

Acredito que a leitura do hipertexto possa ver vista como uma potencialização de vários aspectos da leitura linear como um todo; no entanto, com algumas ressalvas. Benveniste destaca que a enunciação é um fato único a cada ocorrência. Porém, o hipertexto é por si uma infinita oferta de enunciados. No ambiente virtual, os enunciados acabam cruzando-se, 
misturando-se, muitas vezes sofrendo invasões de links ou simultaneidade de telas. A unidade de leitura do discurso, em muitos casos, dá-se pela soma de vários enunciados ao mesmo tempo.

Benveniste diz que a língua manifesta-se na instância do discurso e não somente como um sistema de signos, principalmente em relação ao uso dos pronomes. Considero que o eu, também no hipertexto, seja uma pessoa subjetiva. Já o $t u$, julgo que não possa ser tido totalmente como pessoa não-subjetiva, pois a relação com o interlocutor nem sempre apresenta um tu concreto. Falo, aqui, principalmente, quando lemos, por exemplo, uma publicação no Facebook em que o internauta fala como um tu "imaginário" na sua timeline: "Vc já viu um bebê mais lindo do que este?"6 Na verdade, este "vc" pode designar um $t u$, ou simplesmente uma conversa consigo mesmo (principalmente se a pessoa possui poucos amigos na rede social). Em relação ao ele, penso que continue designado como não-pessoa também em enunciados no ambiente virtual. Acredito que, no entanto, eventualmente, possa ocorrer algum tipo de falha na compreensão da leitura envolvendo todos os pronomes pessoais, principalmente em chats ou espaços para comentários em redes sociais. Nesses ambientes, a velocidade da escrita sem revisão e a rapidez da leitura podem causar comprometimentos, tais como distorção de sentidos, ambiguidades e problemas de interpretação, por exemplo.

Se a linguagem é subjetiva por natureza, acredito que no hipertexto essa subjetividade seja intensificada devido à multiplicidade da oferta de enunciados em um mesmo ambiente. A leitura desses enunciados, ricos de nós hipertextuais com possibilidades de fugas e aprofundamentos, pode confundir o leitor em relação ao seu papel, do seu interlocutor e do que se fala.

${ }^{6}$ Exemplo fictício.
Uma tela de computador conectado à internet é uma rica oportunidade de leitura, porém, não-linear, o que acaba aumentando a necessidade de atenção do leitor, já que várias instâncias discursivas se apresentam em um mesmo local e momento. É sabido que o leitor tem a necessidade de identificar a unicidade de cada discurso, caso contrário terá a compreensão prejudicada. A eficácia desse tipo de leitura vai depender, também, do grau de intimidade que o leitor tem com a plataforma virtual. ${ }^{7}$

Benveniste afirma que a noção de tempo e espaço também constitui a subjetividade da linguagem, já que ambos só atingem significação e completam-se na instância do discurso. Na leitura do hipertexto, considero novamente a potencialização dessa subjetividade, pois tempo e espaço ganham novos significados no ambiente virtual. Em relação ao tempo, o ciberespaço é dotado de instantaneidade, o que pode confundir a noção de presente, passado e futuro. 0 mesmo ocorre com o espaço, uma vez que noções como perto e longe acabam não tendo a mesma importância que na esfera presencial ${ }^{8}$.

Percebo que a leitura do hipertexto acaba tornando-se "leituras" no plural, ou "leitura dentro de leituras". Conforme apresenta Landow (1993), o hipertexto é intertextual, apresenta novas vozes a cada leitura, e é formado por uma rede de textos, cujo centro está sempre em movimento. Associando essa perspectiva com os apontamentos de Benveniste, acredito que seja possível se pensar em uma hipersubjetividade da linguagem no hipertexto. São múltiplas possibilidades de enunciados, que dão ao leitor, inclusive, um novo papel também de autor.

\footnotetext{
Nesse sentido, fala-se da geração y, que, entre suas características, tem a capacidade de absorver diferentes tópicos ao mesmo tempo.

8 Benveniste não tratou da questão "espaço" em sua teoria enunciativa, mas penso que também seja um fator relevante que contribui para a subjetividade dos discursos no ambiente virtual.
} 


\section{Considerações finais}

As análises que resultaram neste estudo teórico, relacionando a teoria da enunciação de Benveniste, as percepções sobre o entendimento da leitura dentro da sua teoria e as teorias sobre hipertexto, levaram-me a constatar a possibilidade exitosa desse cruzamento. Identifiquei que a leitura do hipertexto sob a luz da teoria da enunciação contribui para o entendimento da compreensão (ou falta de compreensão) do leitor no contexto da cibercultura.

Após reflexões sobre o conteúdo apresentado, acredito na viabilidade de se aliar as contribuições de Benveniste - principalmente sobre a subjetividade na linguagem -, também para análises dos discursos publicados em ambiente virtuais, os hipertextos. Constatei que o hipertexto, como o prefixo hiper denuncia, tem no ciberespaço um potencializador da subjetividade de seus textos, daí a proposição de uma hipersubjetividade da linguagem. A multiplicidade do ambiente virtual, com seus textos interligados, intensifica o que serve como teoria para os textos lineares.

Em relação às categorias de pessoa, tempo e espaço no hipertexto, conforme apresentado na seção 3 , apresento algumas propostas fazendo cruzamentos com a teoria de Benveniste. No que diz respeito à hipersubjetividade da categoria pessoa, destaco a proposição de que o tu (pessoa não-subjetiva), no hipertexto, poderia ter sua compreensão alterada. Penso dessa forma, pois a relação com o interlocutor nem sempre apresenta um tu concreto, já que pode haver referência a um tu "imaginário", a um vós ou mesmo ao próprio autor ou a ninguém em especial.

A hipersubjetividade no tocante ao tempo estaria baseada na sua instabilidade, pois presente, passado e futuro muitas vezes se confundem no ciberespaço. $O$ espaço também eleva o grau de subjetividade, dado que no ambiente virtual as distâncias são encurtadas.
Acredito que este artigo possa abrir perspectivas para estudos futuros, seguindo na linha das teorias de Benveniste com as teorias sobre cibercultura, envolvendo teóricos contemporâneos como Manuel Castells (2008), com suas ideias envolvendo o espaço de fluxos e o tempo intemporal, por exemplo. Além disso, é possível se aprofundar as análises com teorias sobre os tipos de leitores, como é o caso das definições propostas por Santaella (2004), que apresenta três: 1) o leitor contemplativo, que é basicamente o leitor de livros, que realiza leitura silenciosa e individual; 2) o leitor movente, fragmentário, que se adaptou a novas formas de leitura; e 3) o leitor imersivo, que é o leitor virtual, que transita "nas potencialmente infinitas infovias do ciberespaço".

Após as análises apresentadas, considero que para o leitor obter maior nível de compreensão da multiplicidade de informações que lhe são oferecidas, é preciso o desenvolvimento de habilidades. Esse novo tipo de leitor, o imersivo, tem superior grau de aproveitamento (ao menos em quantidade de informação) na leitura hipertextual. Nesse contexto, acredito que há um ganho pela capacidade de leitura das unicidades dos discursos, mesmo que de forma simultânea. No entanto, penso que não haja ganho no grau de compreensão e interpretação, tema que pode ser abordado em um estudo futuro, envolvendo pesquisa empírica.

\section{Referências}

BENVENISTE, Émile. Problemas de linguística geral I. Campinas: Pontes, 1988. Problemas de linguística geral II. Campinas: Pontes, 1989.

BUGAY, Edson Luiz; ULBRICHT, Vânia Ribas. Hipermídia. Florianópolis: Bookstore, 2000.

CASTELLS, Manuel. A sociedade em rede. A era da informação: economia, sociedade e cultura. São Paulo: Paz e Terra, 2008. , Vol. I. 
CAVALCANTE, Marianne Carvalho Bezerra. Mapeamento e produção de sentido: os links no hipertexto. In: MARCUSCHI, Luiz Antônio; XAVIER, Antonio Carlos (Orgs.). Hipertexto e gêneros digitais. Rio de Janeiro: Lucerna, 2004.

CHIAPPINI, Lígia. Aprender e ensinar com textos didáticos e paradidáticos. 2. ed. São Paulo: Cortez, 1998. Vol. II.

COSTA, Sérgio Roberto. Minidicionário do discurso eletrônico-digital. Belo Horizonte: Autêntica, 2009. Vol. I.

FLORES, Valdir do Nascimento; SILVA, Silvana; LICHTENBERG, Sônia; WEIGERT, Thaís. Enunciação e gramática. São Paulo: Contexto, 2008.

LANDOW, George P. Ipertesto: il futuro della scrittura. Bologna: Baskerville, 1993.

LAUFER, Roger; SCAVETTA, Domenico. Texto, hipertexto, hipermedia. Portugal: Press Universitaires de France, 19--.

LÉVY, Pierre. Cibercultura. São Paulo: Ed. 34, 1999a.

O que é virtual? São Paulo: Ed. 34, 1996.

As tecnologias da inteligência: o futuro do pensamento na era da informática. Rio de Janeiro: Ed. 34, 1993.

PRIMO, Alex. O aspecto relacional das interações na Web 2.0. E- Compós (Brasília), v. 9, p. 1-21, 2007.

ROSSA, Juliana. Representações de regionalidades e identidades em blogs de brasileiros residentes na Itália. Dissertação (Mestrado) - Programa de Pós-Graduação em Letras, Cultura e Regionalidade, Universidade de Caxias do Sul, 2010.

SANTAELLA, Lúcia. Navegar no ciberespaço: o perfil cognitivo do leitor imersivo. São Paulo: Paulus, 2004

SAUSSURE, Ferdinand de. Curso de linguística geral. 20. ed. São Paulo: Cultrix, 1989.

Recebido em 09/11/2015

Aceito em 06/02/2016 